$$
\left|\begin{array}{cccc}
0 & a_{2} & a_{3} & a^{4} \\
b_{1} & 0 & b_{3} & b_{4} \\
c_{1} & c_{3} & 0 & c_{4} \\
d_{1} & d_{2} & d_{3} & 0
\end{array}\right|=0,
$$

where $a_{2}, a_{3}$, and $a_{1}$ may be taken to be the three areas into which the point $\mathrm{P}$ divides the face $\mathrm{BCD}$; and this condition is the analogue of Menelaus's Theorem for space of three dimensions.

\title{
Historical notes on a geometrical problem and theorem.
}

$$
\text { By J. S. Mackay. M.A., LI.D. }
$$

The problem is

Between two sides of a triangle to inflect a straight line which shall be equal to each of the segments of the sides between it and the base.

This problem was brought before the Society at the January meeting in 1884, and a solution of it by $\mathrm{Mr}$ James Edward will be found in our Proceedings, Vol. II, pp. 5-6, a second by myself in Vol. II., p. 27 (10th April 1884), a third by Mr R. J. Dallas in Vol. III., pp. 41-2 (9th January 1885). Solutions of a slightly more general problem were also given by myself in Vol. III., pp. 40-1, and reference made to the Educational Times, Vol. 37, p. 328 (1st October 1884), and to Yruibert's Journal de Mathématiques Élémentaires, $9^{\mathrm{e}}$ année, p. 45 (15th December 1884).

I have since found that the more general problem was proposed by Monsieur J. Neuberg in the Nouvelle Correspondance Mathématique, Vol, I., p. 110 (1874-5), and solved by him in Vol. II, p. 248 (1876); and quite recently I have discovered the first problem to go as far back as 1773-4. Here is how it occurs.

In the Ladies' Diary for $1773, \mathrm{Mr}$ Thomas Moss proposes for solution the following:--

The difference of the sicles including a known angle of a plane triangle being given, and also the sum of one of those sides and that opposite the given angle, to construct the triangle.*

In 1774 the question is thus answered by Mr John Turner :-

"Analysis. Suppose the thing done, and that $\mathrm{ABC}$ is the

Thomas Leybourn's Muthematical Questions propsed in the Ladies' Diary, Vol. II., p. 377 (1817). 
triangle, of which are given the angle $A$, the sum $A C+C B$, and the difference $\mathrm{AB}-\mathrm{AC}$. Then also will be given $\mathrm{AB}+\mathrm{BC}$, it being evidently equal to $\mathrm{AC}+\mathrm{CB}$ + the given difference $\mathrm{AB}-\mathrm{AC}$; and therefore if $A D$ and $A E$ be made respectively equal to the given sums $A B+B C$ and $A C+C B$, the triangle $A D E$ will also be given ; and then between the sides of this given triangle we have only to apply $\mathrm{BC}$ so as to cut off $\mathrm{BD}$ and $\mathrm{CE}$ each equal to it; whence appears this easy

"Construction. Form (Fig. 44) the given angle DAE and make $\mathrm{DA}$ and AE equal to the two given sums of each side and the base; draw any line FG parallel to DE, and make EH and HI each equal to $\mathrm{DF}$; then draw EIB, and lastly $\mathrm{BC}$ parallel to $\mathrm{HI}$ cutting off the triangle $\mathrm{ABC}$ required."

The demonstration is omitted as unnecessary.

The theorem is

The middle points of the three diagonals of a complete quadrilateral are collinear.

It was Carnot (Essai sur la theorie des transversales, 1806, \& 6) who bestowed the name complete quadrilateral on a system of four straight lines no three of which are concurrent, but he does not seem to have been aware of this property of the three diagorals. In Cremona's Eloments of Projective Geometry the property is ascribed to Gauss (Collected Works, Vol. IV., p. 391), and Dr Baltzer says, "Diese Eigenschaft des Vierecks ist von Gauss 1810 bemerkt worden (v. Zach monatl. Korresp. 22, p. 115)."

In the Ladies' Diary for 1795 the following question is proposed by $\mathrm{Mr}$ J. T. Connor, Lewes Academy, and in 1796 two solutions of it are given, the first by Major Henry Haldane of the Royal Engineers, and the second by Mr John Ryley of Leeds.

In a triangle $A B C$, drawing any two lines $A E, B D$ from the extremities of one side, to terminate in the other two sides; and thereby form a trapezium $C D K E$; if the diagonals $D E$ and $C K$ of that trapezium be bisected in the points $M$ and $N$, and the first side of the triangle in the point $P$, these three points $P, M, N$ will be in a straight line. Required the demonstration." *

* Thomas Leybourn's Mathematical Questions proposed in the Ladies' Diary, Vol. III., p. 291 (1817). 